\title{
IMPLEMENTASI WAKAF ISTIBDAL DALAM PEMBEBASAN LAHAN PEMBANGUNAN JALAN TOL (STUDI KASUS PEMBANGUNAN JALAN TOL SURABAYA-MOJOKERTO)'
}

\author{
Fikri Ariza Achmad \\ Departemen Ekonomi Syariah-Fakultas Ekonomi dan Bisnis-Universitas Airlangga \\ Email: fikri.ariza.achmad-2015@feb.unair.ac.id \\ Irham Zaki \\ Departemen Ekonomi Syariah-Fakultas Ekonomi dan Bisnis-Universitas Airlangga \\ Email: irham-z@feb.unair.ac.id
}

\begin{abstract}
:
The background of this research is the existence of massive infrastructure development by the government, one of which is the construction of the SurabayaMojokerto Toll Road. The construction process of the Surabaya-Mojokerto Toll Road passes through the land and buildings owned by residents, and including to wagf land. One of the wagf land affected by the construction process of the Surabaya-Mojokerto Toll Road is the Sabilun Najah Mosque. This phenomenon encourages researchers to raise research that discusses how the waqf istibdal process, both in terms of changes in waqf assets and in the administration process of licensing. This study uses a qualitative approach with a case study strategy. Data collection is done through interview techniques with relevant parties and related documents. The data analysis technique used is making explanations. The results of this study indicate that the process of changing the wagf assets of the Sabilun Najah Mosque runs in accordance with statutory procedures. The waqf istibdal process consists of the process of changing the waqf property and the licensing administrative process. The process of changing waqf property consists of planning, implementation, coordination between toll management and nazir, searching for replacement land, replacing land replacement processes, and the process of building a new mosque. The second process consists of a licensing process that starts from nazir, the Office of the Ministry of Religion Sidoarjo Regency, and the Regional Office of the Ministry of Religion of East Java.
\end{abstract}

Keywords: implementation, waqf, waqf istibdal, mosque, land acquisition, toll road, Surabaya-Mojokerto Toll Road

\section{PENDAHULUAN}

Islam selalu mengajarkan manusia untuk berbuat baik kepada sesama. Salah satu cara untuk berbuat baik kepada sesama adalah dengan cara memberi. Kegiatan tabarru' (sukarela) dalam Islam sangatlah banyak, beberapa di antaranya adalah zakat, infak, sedekah, dan wakaf. Wakaf merupakan salah satu bentuk ibadah yang disukai oleh Allah SWT.
Wakaf tidak hanya memberikan dampak dalam bidang keagamaan saja, namun juga mencakup bidang ekonomi dan sosial.

Halim (2015), memaparkan bahwa wakaf adalah salah satu bagian yang sangat penting dari hukum Islam, karena mempunyai jalinan hubungan antara kehidupan spritual dengan bidang sosial ekonomi masyarakat muslim. Wakaf juga berperan sebagai

\footnotetext{
${ }^{1}$ Jurnal ini merupakan bagian dari skripsi Fikri Ariza Achmad, NIM: 041511433145, yang diuji pada tanggal 19 Juli 2019.
} 
Achmad, et al/Jurnal Ekonomi Syariah Teori dan Terapan Vol. 6 No. 9 September 2019: 1924-1935;

IMPLEMENTASI WAKAF ISTIBDAL DALAM PEMBEBASAN LAHAN PEMBANGUNAN JALAN TOL (STUDI

KASUS PEMBANGUNAN JALAN TOL SURABAYA-MOJOKERTO)

perekat hubungan, hubungan vertikal kepada Allah SWT dan hubungan horizontal kepada sesama manusia.

Wakaf sendiri di dalam Alquran tidak dijelaskan secara jelas, tetapi terdapat ayat Alquran yang menjalaskan tentang perintah Allah untuk menafkahkan harta yang dimiliki kepada orang lain. Hal tersebut dalam Surat Al-Baqarah ayat 267:

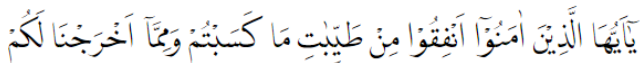

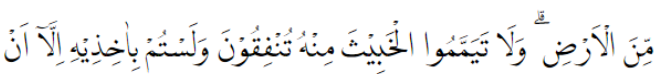

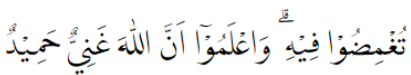

Yā ayyuhallażina āmanū anfiqu min țayyibāti mā kasabtum wa mimmā akhrajnā lakum minal-arḍ, wa lā tayammamul-khabīsa min-hu tunfiquna wa lastum bi ākhiżihi illā an tugmiḍu fih, wa'lamū annallāha ganiyyun hamìd

Artinya: "Hai orang-orang yang beriman, nafkahkanlah (di jalan Allah) sebagian dari hasil usahamu yang baikbaik dan sebagian dari apa yang Kami keluarkan dari bumi untuk kamu. Dan janganlah kamu memilih yang burukburuk lalu kamu menafkahkan daripadanya, padahal kamu sendiri tidak mau mengambilnya melainkan dengan memincingkan mata terhadapnya. dan ketahuilah, bahwa Allah Mahakaya lagi Maha Terpuji. (Q.S. Al-Baqarah: 267)

Berdasar pada pasal 1 ayat (1) Undang-Undang Nomor 41 Tahun 2004 Tentang Wakaf, wakaf adalah perbuatan hukum wakif untuk memisahkan dan/atau menyerahkan sebagian harta benda miliknya untuk dimanfaatkan selamanya atau untuk jangka waktu tertentu sesuai dengan kepentingannya guna keperluan ibadah dan/atau kesejahteraan umum menurut syariah.

Pada praktek pelaksanaannya, harta pokok wakaf harus ditahan oleh wakif dan hasilnyalah yang akan diberikan untuk kepentingan umum. Harta pokok tersebut tidak dapat dialihfungsikan, diwariskan, dipindahtangankan, dijual, dan sebagainya. Akan tetapi, timbul sebuah pertanyaan, yakni jka pada suatu saat harta wakaf itu sudah tidak lagi atau kurang memberi manfaat, apakah harus dilakukan perubahan pada harta wakaf tersebut seperti menjual, merubah bentuk atau sifat, memindahkan ke tempat lain atau menukar dengan benda lain? Serta apakah perubahan itu boleh dilakukan terhadap pada harta wakaf tersebut?

Menukar atau menjual harta wakaf dalam istilah fikih dikenal ibdal atau istibdal. Badan Wakaf Indonesia menjelaskan bahwa al-Istibdal adalah mengeluarkan suatu barang dari status wakaf, dan menggantikannya dengan barang lain. Kasus perubahan atau tukar-menukar harta-benda wakaf ini terjadi perbedaan pendapat di kalangan ulama fikih. Imam Al-Sarkhasi yang menganut mazhab Hanafi adalah 
Achmad, et al/Jurnal Ekonomi Syariah Teori dan Terapan Vol. 6 No. 9 September 2019: 1924-1935;

IMPLEMENTASI WAKAF ISTIBDAL DALAM PEMBEBASAN LAHAN PEMBANGUNAN JALAN TOL (STUDI KASUS PEMBANGUNAN JALAN TOL SURABAYA-MOJOKERTO)

membolehkan istibdal harta wakaf sedangkan Imam Al-Nawawi yang menganut mazhab Syafi'i, beliau berpendapat bahwa harta wakaf yang sudah tidak berfungsi tetap tidak boleh dijual, ditukar atau diganti dan dipindahkan.

Banyaknya silang pendapat yang terjadi di kalangan ulama fikih, menjadikan wakaf istibdal cenderung dihindari. Di Indonesia, kegiatan menukar atau menjual tanah atau benda-benda wakaf sering menjadi persoalan dan terkadang menimbulkan konflik. Penelitian tentang wakaf istibdal masih sangat terbatas. Banyak penelitian hanya berfokus pada hukum dari wakaf istibdal, untuk penelitian tentang implementasi atau pelaksaan dari wakaf istibdal sangatlah sedikit, bahkan hampir tidak ada.

Presiden Joko Widodo melalui program nawacita, memiliki sembilan program prioritas. Program ini digagas untuk menunjukkan prioritas jalan perubahan menuju Indonesia yang berdaulat secara politik, serta mandiri dalam bidang ekonomi dan berkepribadian dalam kebudayaan.

Saat ini pemerintah sedang mendorong pembangunan infrastruktur yang kuat agar dapat bersaing dengan negara lain. Hal ini bisa dilihat bahwa dari tahun 2009 sampai 2017, anggaran infrastruktur selalu meningkat dan selalu diatas $8 \%$. Salah satu pembangunan infrastruktur yang digiatkan pemerintah saat ini adalah jalan tol. Mengapa jalan tol? Karena jalan tol dapat meningkatkan konektivitas antardaerah dan dapat meningkatkan efisiensi logistik barang dan jasa.

Salah satu jalan tol yang diselesaikan pada masa pemerintahan Presiden Joko Widodo adalah pembangunan Jalan Tol Trans-Jawa, dimana salah satu ruas tol Jalan Tol Trans-Jawa adalah Jalan Tol SurabayaMojokerto. Jalan Tol Sumo membentang sepanjang 36,27 kilometer yang menghubungkan Kota Surabaya dengan Kota Mojokerto. Jalan tol ini beroperasi penuh sejak tahun 2017 dan dikelola oleh PT. Jasa Marga Surabaya Mojokerto.

Salah satu kendala yang dapat dikatakan selalu ada dalam setiap pembangunan jalan tol adalah masalah pembebasan lahan. Tarik ulur dengan masyarakat terutama karena harga ganti-rugi tanah selalu menjadi persoalan. Belum lagi jika terdapat area tanah wakaf yang menjadi bagian dari area yang dilewati pembangunan jalan tol. Maka proses pembebasan lahannya menjadi lebih rumit. Salah satu jalan keluar dari permasalahan tersebut adalah dengan penerapan wakaf istibdal dalam pembebasan lahan tesebut.

\section{LANDASAN TEORI}

Badan Wakaf Indonesia membahas masalah tukar-menukar barang wakaf dalam istilah fikih 
Achmad, et al/Jurnal Ekonomi Syariah Teori dan Terapan Vol. 6 No. 9 September 2019: 1924-1935; IMPLEMENTASI WAKAF ISTIBDAL DALAM PEMBEBASAN LAHAN PEMBANGUNAN JALAN TOL (STUDI KASUS PEMBANGUNAN JALAN TOL SURABAYA-MOJOKERTO)

perwakafan disebut "istibdal" atau "ibdal". Al-Istibdal adalah mengeluarkan suatu barang dari status wakaf, dan menggantikannya dengan barang lain. Selanjutnya al-lbdal diartikaan sebagai penggantian barang wakaf dengan barang wakaf lainnya, baik yang sama kegunaannya atau tidak, seperti menukar wakaf yang berupa tanah pertanian dengan barang lain yang berupa tanah untuk bangunan.

Proses wakaf istibdal tentu harus dapat disikapi dengan bijak. Karena apabila membuka pintu praktek istibdal seluas-seluasnya dengan membolehkan menjual barang wakaf, dapat menimbulkan akibat-akibat negatif. Sebaliknya, akibat dari pendapat yang terlalu mempersulit istibdal, meskipun sebuah harta wakaf sudah tidak dapat memberi manfaat apapun sebagaimana yang diharapkan, dapat menimbulkan keterlantaran dan hilangnya daya guna harta wakaf itu sendiri.

\section{Perubahan} dan pengalihfungsian tanah wakaf telah diatur dalam aturan perundangundangan, yaitu Undang-Undang Nomor 41 Tahun 2004 tentang Wakaf, Peraturan Pemerintah Nomor 42 Tahun 2006 tentang Pelaksanaan UndangUndang Nomor 41 Tahun 2004 tentang Wakaf dan Kompilasi Hukum Islam, dan Peraturan Pemerintah Republik Indonesia Nomor 25 Tahun 2018 tentang
Perubahan Atas Peraturan Pemerintah Nomor 42 Tahun 2006 Tentang Pelaksanaan Undang-Undang Nomor 41 Tahun 2004 Tentang Wakaf Dalam Undang-Undang Nomor 41 Tahun 2004 tentang Wakaf.

Jalan Tol Surabaya-Mojokerto atau yang sering disingkat Tol Sumo adalah jalan tol yang membentang sepanjang 36,27 kilometer yang menghubungkan Kota Surabaya dengan Kota Mojokerto. Jalan tol ini beroperasi penuh sejak tahun 2017. Jalan Tol Surabaya-Mojokerto merupakan bagian dari Jalan Tol Trans Jawa dan menjadi akses utama yang menghubungkan Surabaya dan Jakarta via jalan tol. Pembangunan jalan tol ini dimulai pada tahun 2007 dan dioperasionalkan secara bertahap. Seksi IA sepanjang 2,3 kilometer (WaruSepanjang, diresmikan 27 Agustus 2011), seksi IV sepanjang 18,47 kilometer (KrianKota Mojokerto, diresmikan 19 Maret 2016), serta seksi IB 4,3 km (SepanjangWRR); seksi II 5,1 km (WRR-Driyorejo); dan seksi III 6,1 km (Driyorejo-Krian) diresmikan 19 Desember 2017.

\section{METODE PENELITIAN}

\section{Pendekatan Penelitian}

Penelitian ini menggunakan pendekatan kualitatif. Strategi yang digunakan dalam penelitian ini adalah studi kasus. Menurut Yin (2013:1), Studi kasus merupakan strategi yang paling cocok bila pertanyaan suatu penilitian berkenan dengan how atau why, bila 
Achmad, et al/Jurnal Ekonomi Syariah Teori dan Terapan Vol. 6 No. 9 September 2019: 1924-1935; IMPLEMENTASI WAKAF ISTIBDAL DALAM PEMBEBASAN LAHAN PEMBANGUNAN JALAN TOL (STUDI KASUS PEMBANGUNAN JALAN TOL SURABAYA-MOJOKERTO)

peneliti hanya memiliki sedikit peluang untuk mengontrol peristiwa peristiwa yang akan di selidiki dan bilamana fokus penelitian terletak pada fenomena masa kini di dalam konteks kehidupan nyata.

\section{Ruang Lingkup Penelitian}

Batasan atau ruang lingkup penelitian ini difokuskan pada proses perubahan harta-benda wakaf Masjid Sabilun Najah dari proses perencanaan pembangunan jalan tol sampai masjid pengganti dibangun. Penelitian ini juga memaparkan bagaimana proses perizinan administrasi perubahan hartabenda wakaf Masjid Sabilun Najah yang terletak di Kelurahan Bebekan, Kecamatan Taman, Kabupaten Sidoarjo.

\section{Jenis dan Sumber Data}

Sumber data yang digunakan dalam penelitian ini adalah data primer dan data sekunder. Data primer adalah yang diperoleh langsung dari sumbernya melalui wawancara dengan pihak-pihak yang berkepentingan dalam proses perubahan harta-benda wakaf di Masjid Sabilun Najah. Data sekunder penelitian ini diperoleh dari studi kepustakaan, arsip dan dokumen terkait proses pelaksanaan wakaf istibdal dan proses administrasi perizinannya.

\section{Unit Analisis}

Unit analisis dalam penelitian ini adalah implementasi wakaf istibdal dalam pembebasan lahan pembangunan Jalan Tol SurabayaMojokerto, yang termasuk didalamnya terdapat aktivitas proses perizinan dari pihak nazir Majelis Wakil Cabang Nahdlatul 'Ulama Kecamatan Taman sampai mendapat persetujuan dari Kantor Wilayah Kementerian Agama Provinsi Jawa Timur dan musyawarah antar-pihak yang berkepentingan.

\section{Teknik Pengumpulan Data}

Langkah-langkah

yang

dilakukan dalam prosedur pengumpulan data adalah:

1. Peneliti melakukan persiapan awal dengan menyiapkan surat dari Fakultas Ekonomi dan Bisnis Universitas Airlangga untuk izin mewawancarai.

2. Peneliti melakukan wawancara dengan pihak nazir beserta takmir Masjid Sabilun Najah, Tim Pengadaan Tanah Jalan Tol Sumo, Kantor Kementerian Agama Kabupaten Sidoarjo, Kantor Wilayah Kementerian Agama Jawa Timur, Ketua RT 08 RW 03 Kelurahan Bebekan, dan pihak yang lahannya dibeli untuk dijadikan lokasi pembangunan masjid yang baru.

\section{Teknik Keabsahan Dato}

Penelitian ini menggunakan teknik triangulasi untuk menguji keabsahan data. Teknik triangulasi adalah teknik pemeriksaan yang memanfaatkan sesuatu yang lain. Terdapat tiga teknik triangulasi yaitu triangulasi sumber, triangulasi teknik, 
Achmad, et al/Jurnal Ekonomi Syariah Teori dan Terapan Vol. 6 No. 9 September 2019: 1924-1935; IMPLEMENTASI WAKAF ISTIBDAL DALAM PEMBEBASAN LAHAN PEMBANGUNAN JALAN TOL (STUDI KASUS PEMBANGUNAN JALAN TOL SURABAYA-MOJOKERTO)

dan triangulasi waktu. Triangulasi yang digunakan dalam penelitian ini adalah triangulasi sumber yaitu dengan membandingkan keselarasan hasil wawancara antara pihak yang terkait yaitu pihak nazir beserta takmir Masjid Sabilun Najah, Tim Pengadaan Tanah Jalan Tol Sumo, Kantor Kementerian Agama Kabupaten Sidoarjo, Kantor Wilayah Kementerian Agama Jawa Timur, Ketua RT 08 RW 03 Kelurahan Bebekan, dan pihak yang lahannya dibeli untuk dijadikan lokasi pembangunan masjid yang baru.

\section{Teknik Analisis Data}

Dalam penelitian ini, peneliti menggunakan teknik pembuatan eksplanasi. Menurut Yin (2013) pembuatan eksplanasi untuk menjelaskan fenomena atau menetapkan serangkaian timbal balik mengenai fenomena tersebut. Dari proses analisis ini semua data yang diperoleh akan diolah kembali, dihubungkan, dan dibandingkan sehingga dapat diketahui masingmasing terkait proses wakaf istibdal di Masjid Sabilun Najah.

\section{HASIL DAN PEMBAHASAN}

Menurut Peraturan Pemerintah Nomor 42 Tahun 2006 Tentang Pelaksanaan Undang-Undang Nomor 41 Tahun 2004 Tentang Wakaf, Wakaf adalah perbuatan hukum wakif untuk memisahkan dan/atau menyerahkan sebagian harta benda miliknya untuk dimanfaatkan selamanya atau untuk jangka waktu tertentu sesuai dengan kepentingannya guna keperluan ibadah dan/atau kesejahteraan umum menurut syariah.

Prof. Dr. KH. Tolchah Hasan, mantan ketua Badan Wakaf Indonesia, menjelaskan secara singkat bahwa wakaf istibdal adalah penjualan barang wakaf untuk dibelikan barang lain sebagai wakaf penggantinya.

Berdasarkan

Peraturan

Pemerintah Nomor 25 Tahun 2018 Tentang Perubahan Atas Peraturan Pemerintah Nomor 42 Tahun 2006 Tentang Pelaksanaan Undang-Undang Nomor 41 Tahun 2004 Tentang Wakaf, suatu harta-benda wakaf hanya diperbolehkan mengalami proses istibdal apabila memenuhi tiga syarat, yaitu digunakan untuk kepentingan umum sesuai dengan rencana umum tata ruang (RUTR), harta-benda wakaf tidak dapat dipergunakan sesuai dengan ikrar Wakaf, atau pertukaran dilakukan untuk keperluan keagamaan secara langsung dan mendesak.

Proses pembangunan Jalan Tol Surabaya-Mojokerto dimulai dengan terbitnya Surat Keputusan Gubernur Jawa Timur Nomor 188/164/KPTS/013/2006 Tentang Persetujuan Penetapan Lokasi Pembangunan Jalan Tol Bebas Hambatan (Tol) Surabaya-Mojokerto. Jalan tol ini melewati satu kota dan tiga kabupaten serta mencakup lahan seluas 359,853 hektare. 
Achmad, et al/Jurnal Ekonomi Syariah Teori dan Terapan Vol. 6 No. 9 September 2019: 1924-1935;

IMPLEMENTASI WAKAF ISTIBDAL DALAM PEMBEBASAN LAHAN PEMBANGUNAN JALAN TOL (STUDI KASUS PEMBANGUNAN JALAN TOL SURABAYA-MOJOKERTO)

Proses selanjutnya yang dilakukan adalah proses pelaksanaan. Setelah diterbitkannya surat keputusan gubernur tentang penetapan lokasi, pihak tol selanjutnya melakukan pendataan terkait tanah dan bangunan yang akan terdampak pembangunan jalan tol. Setelah proses pendataan selesai dilakukan, maka pihak tol akan mengumumkan hasilnya kepada masyarakat sehingga akan diketahui oleh masyarakat apakah tanah atau bangunannya terdampak pembangunan jalan tol atau tidak.

Proses ganti-untung bagi tanah atau bangunan yang terdampak pembangunan jalan tol tidak sertamerta dilakukan dengan pemberian vang. Berdasarkan bentuk barang penggantinya, pihak-pihak yang menerima ganti-untung dibagi menjadi dua kelompok. Kelompok pertama adalah pemilik tanah perorangan, perusahaan swasta, dan BUMN atau BUMD yang tidak terikat aturan sehingga dalam menerima barang ganti-untung dapat memilih, apakah menginginkan vang tunai atau tanah/bangunan di tempat lain. Kelompok kedua adalah yang terikat oleh aturan perundang-undangan, seperti tanah wakaf yang merujuk pada peraturan dan tanah atau bangunan milik instansi pemerintah. Contohnya adalah tanah wakaf yang diatasnya berdiri bangunan, dimana bentuk barang ganti-untungnya harus berupa tanah dan bangunan juga. Dengan demikian, dalam kasus Masjid Sabilun Najah, maka pihak Jalan Tol SurabayaMojokerto bermusyarawah dengan Majelis Wakil Cabang Nahdlatul Ulama Kecamatan Taman sebagai nazir.

Beberapa pengurus takmir dan beberapa warga setempat menolak keras proses istibdal Masjid Sabilun Najah. Pengurus takmir masjid ada yang berpegang pada pendapat dari Imam Syafi'i yang menyatakan bahwa harta wakaf tidak dapat diganti, dipindah, dijual atau diubah bentuknya sampai kapan pun. Pihak nazir membujuk dengan cara menunjukkan undangundang tentang wakaf istibdal kepada pihak-pihak yang masih meragukan hukum dari wakaf istibdal. Pihak nazir juga memberikan pengertian bahwa pembangunan jalan tol adalah untuk kepentingan umum. Pembangunan jalan tol untuk kemaslahatan dan kemakmuran warga negara.

Setelah melalui proses negosiasi yang cukup lama, pihak-pihak yang awalnya menolak dan tidak menyetujui adanya wakaf istibdal pada akhirnya setuju dan menerima. Selanjutnya akan dicarikan tanah pengganti untuk masjid. Proses pencarian tanah pengganti dilakukan oleh negara, dalam hal ini adalah Tim Pengadaan Tanah Jalan Tol Surabaya-Mojokerto. Akan tetapi Tim Pengadaan Tanah juga meminta saran dan melakukan musyawarah dengan para pengurus 
Achmad, et al/Jurnal Ekonomi Syariah Teori dan Terapan Vol. 6 No. 9 September 2019: 1924-1935;

IMPLEMENTASI WAKAF ISTIBDAL DALAM PEMBEBASAN LAHAN PEMBANGUNAN JALAN TOL (STUDI KASUS PEMBANGUNAN JALAN TOL SURABAYA-MOJOKERTO)

takmir masjid terkait lokasi masjid yang baru.

Proses pencarian tanah pengganti pun berlangsung lama. Terjadi banyak kendala dalam proses pencarian tanah pengganti. Salah satu contohnya adalah permintaan harga yang terlalu tinggi dari pemilik tanah yang tanahnya akan dibeli oleh Tim Pengadaan Tanah untuk dipakai membangun masjid yang baru. Pada akhirnya pihak tol menemukan enam pemilik tanah yang tanahnya akan dibeli untuk dijadikan wakaf pengganti. Lokasi tanah pengganti ini berdekatan dan dianggap sangat cocok.

Tim Pengadaan Tanah dalam memberikan harta pengganti tentu tidak sembarangan, dan itulah mengapa namanya adalah gantiuntung, bukan ganti-rugi. pada proses pemberian ganti-untung, pihak tol berpedoman pada dua hal, nilai fisik dan non fisik. Nilai fisik adalah harga pasaran tanah tersebut. Pemerintah telah memiliki data terkait harga tanah dan kelas-kelasnya di semua tempat. Kedua adalah non-fisik, yang berarti adalah biaya yang dikeluarkan pemilik tanah atau bangunan yang terdampak jalan tol untuk memiliki tanah atau bangunan baru sampai dapat menjalani kehidupan sehari-hari seperti semula. Dengan demikian, pihak tol selalu memberikan ganti yang lebih kepada pihak-pihak yang tanahnya dibeli oleh pinak tol.
Takmir masjid Sabilun Najah kemudian mengadakan rapat dengan para pemilik tanah. Dalam Surat Keputusan Rapat Ta'mir Masjid Sabilun Najah tanggal 20 Juni 2015 Nomor 003/TMS/KB/VI/2015, terdapat dua poin yang disepakati, yaitu relokasi tanah pengganti Masjid Sabilun Najah telah disepakati berada \pm 25 meter sebelah selatan Masjid Sabilun Najah dan tanah tersebut memiliki luas $611 \mathrm{~m}^{2}$ yang terdiri dari beberapa pemilik tanah, antara lain Choirul Anam Manab, Mochammad Yani Ansori, Dra. Sofiyah, Muchammad Fathoni, Abdullah As'ari, dan Dr. Ir. Minto Waluyo, MM.

Tim Pengadaan tanah kemudian memberikan uang kepada keenam pemilik tanah tersebut sebagai tanda bahwa tanah tersebut telah dibeli oleh pihak tol. Proses pemberian uangnya melalui pembukaan rekening oleh pihak tol kemudian buku tabungannya diserahkan kepada pemilik tanah yang tanahnya dibeli oleh pihak tol.

Setelah pembayaran vang ganti-untung selesai, pihak tol kemudian merobohkan bangunannya dan membangun masjid yang baru. Proses pembangunan masjid yang baru ini kembali melibatkan takmir dan nazir.

Ketika pembangunan masjid yang baru telah selesai, maka pihak tol akan merobohkan masjid yang lama dan membangun Jalan Tol SurabayaMojokerto diatasnya. Pada tahap ini tanah dan bangunan masjid masih 
Achmad, et al/Jurnal Ekonomi Syariah Teori dan Terapan Vol. 6 No. 9 September 2019: 1924-1935;

IMPLEMENTASI WAKAF ISTIBDAL DALAM PEMBEBASAN LAHAN PEMBANGUNAN JALAN TOL (STUDI KASUS PEMBANGUNAN JALAN TOL SURABAYA-MOJOKERTO)

menjadi milik pihak tol. Bangunan masjid yang baru akan menjadi milik Majelis Wakil Cabang Nahdlatul Ulama Kecamatan Taman apabila telah terbit surat keputusan pemberian izin tukarmenukar harta-benda wakaf dari Kepala Kantor Wilayah Kementerian Agama Jawa Timur.

Memperhatikan kriteria alasan diadakannya istibdal harta-benda wakaf dan luas tanah wakaf, maka Majelis Wakil Cabang Nahdlatul Ulama Kecamatan Taman selaku nazir wakaf Masjid Sabilun Najah mengajukan permohonan tukar-menukar hartabenda wakaf Masjid Sabilun Najah kepada Kepala Kantor Kementerian Agama Provinsi Jawa Timur melalui Kepala Kantor Kementerian Agama Kabupaten Sidoarjo.

Kantor Urusan Agama

Kecamatan Taman dalam proses perizinan wakaf istibdal hanya membantu jalannya proses perizinan agar berjalan lancar dan cepat. Kantor Urusan Agama hanya berperan sebagai fasilitator, yakni berperan menerbitkan surat dan hal-hal yang diperlukan serta saksi apabila diperlukan. Selain itu, Kantor Urusan Agama juga dapat berperan sebagai mediator.

Kementerian Agama Kabupaten Sidoarjo yang menerima berkas dari nazir, kemudian melakukan pengoreksian berkas. Apabila berkas dinyatakan lengkap, Kepala Kantor
Kementerian Agama Kabupaten Sidoarjo membentuk Tim Penilai yang bertugas untuk menilai harta-benda wakaf berserta penggantinya.

Tim Penilai kemudian melakukan survei ke lokasi dimana obyek hartabenda wakaf tersebut berada. Survei lapangan diperlukan untuk membandingkan kondisi asli di lapangan dengan pemaparan dalam berkas.

Setelah Tim Penilai melakukan survei lapangan dan beberapa kali rapat, Tim Penilai kemudian menerbitkan berita acara yang berisi hasil penilaian terhadap harta-benda wakaf. Berita acara tersebut juga terlampir hasil penilain oleh Tim Penilai. Berdasarkan hasil penilaian, nilai hartabenda wakaf masjid yang lama sebesar Rp 3.247.998.396,- dan nilai harta-benda wakaf pengganti adalah sebesar Rp 5.426.935.955,-. Karena nilai hartabenda pengganti lebih besar daripada harta-benda wakaf, maka wakaf istibdal masjid dianggap telah sah. Tim Penilai kemudian menyerahkan berita acara hasil penilaian kepada Kepala Kantor Kementerian Agama Kabupaten Sidoarjo.

Apabila hasil penilaian dinilai layak \& sesuai dengan peraturan, maka Kepala Kantor Kementerian Agama akan mengirimkan surat kepada Kepala Kantor Wilayah Kementerian Agama Jawa Timur dan Badan Wakaf Indonesia Jawa Timur bahwa proses perizinan 
Achmad, et al/Jurnal Ekonomi Syariah Teori dan Terapan Vol. 6 No. 9 September 2019: 1924-1935;

IMPLEMENTASI WAKAF ISTIBDAL DALAM PEMBEBASAN LAHAN PEMBANGUNAN JALAN TOL (STUDI KASUS PEMBANGUNAN JALAN TOL SURABAYA-MOJOKERTO)

dapat dilanjutkan dan melampirkan berkas-berkas pengajuan perubahan harta-benda wakaf yang diajukan oleh nazir. Tim Penilai kemudian juga memberikan surat rekomendasi kepada Tim Penetapan terkait hasil penilaian.

Sebelumnya, Kepala Kantor Wilayah Kementerian Agama Jawa Timur telah membentuk Tim Penetapan lima hari sejak menerima surat permohonan dari nazir. Ketika Kantor Wilayah Kementerian Agama Jawa Timur menerima berkas dari Kantor Kementerian Agama Kabupaten Sidoarjo, maka akan dilakukan kembali proses pengoreksian berkas-berkas.

Apabila berkas telah dinyatakan lengkap, Tim Penetapan akan melakukan survei lapangan hartabenda wakaf dan penggantinya. Tim Penetapan melakukan survei lapangan untuk menyocokkan data-data yang terlampir di berkas dan keadaan riil di lapangan. Hal ini bertujuan agar tidak terjadi kesalahan-kesalahan yang tentunya akan menimbulkan masalah di masa yang akan datang.

Apabila hasil survei lapangan telah dinilai layak dan sesuai dengan peraturan perundang-undangan, maka Tim Penetapan akan memberikan rekomendasi Kepala Kantor Kementerian Agama untuk menerbitkan surat keputusan perubahan hartabenda wakaf.

Kepala Kantor Wilayah Kementerian Agama Jawa Timur menerbitkan surat keputusan perubahan harta-benda wakaf Masjid Sabilun Najah berdasarkan surat rekomendasi dari Tim Penetapan dan Badan Wakaf Indonesia Jawa Timur.

\section{SIMPULAN}

Berdasarkan hasil dari pembahasan dapat disimpulkan bahwa proses wakaf istibdal di Masjid Sabilun Najah yang terjadi karena adanya pembangunan Jalan Tol Surabaya-Mojokerto secara garis besar berjalan lancar. Selain itu, dalam proses pengajuan perizinan perubahan hartabenda wakaf juga sudah sesuai dengan peraturan perundang-undangan yang berlaku. Akan tetapi, proses perizinan berlangsung sangat lama, yaitu selama empat tahun (2015-2019).

Selama proses istibdal yang terjadi di Masjid Sabilun Najah, ditemukan beberapa permasalahan. Hal pertama yang menjadi permasalahan wakaf istibdal selama ini adalah kurangnya pengetahuan masyarakat tentang wakaf istibdal itu sendiri. Pertama adalah banyaknya pendapat dan mazhab yang bertentangan mengenai hukum dari pelaksanaan wakaf istibdal tentu dapat dikatakan "menghambat" proses wakaf istibdal. Hal ini bisa diatasi dengan menunjukkan Undang-Undang Nomor 41 Tahun 2004 , Peraturan Pemerintah Nomor 42 Tahun 2006, dan Peraturan Pemerintah Republik Indonesia Nomor 25 Tahun 2018. 
Achmad, et al/Jurnal Ekonomi Syariah Teori dan Terapan Vol. 6 No. 9 September 2019: 1924-1935;

IMPLEMENTASI WAKAF ISTIBDAL DALAM PEMBEBASAN LAHAN PEMBANGUNAN JALAN TOL (STUDI KASUS PEMBANGUNAN JALAN TOL SURABAYA-MOJOKERTO)

Kedua adalah alotnya proses negosiasi harga antara Tim Pengadaan Tanah dengan masjid yang tanah dan bangunannya yang terdampak jalan tol. Pemilik tanah biasanya meminta harga yang lebih tinggi dari yang dibayarkan oleh pihak tol. Pihak tol sebenarnya selalu memberikan harta pengganti yang lebih, tidak hanya menghitung harga fisik bangunan saja, tetapi juga non-fisik.

Terakhir adalah lamanya persoalan administrasi. Meskipun dalam peraturan perundang-undangan telah dijelaskan secara jelas proses-proses tahapan permohonan beserta waktu tunggu birokrasinya dari tingkat nazir sampai tingkat provinsi atau pusat, tetap saja terjadi terjadi keterlambatan. Maka dari itu, terbitlah Peraturan Pemerintah Republik Indonesia Nomor 25 Tahun 2018 tentang Perubahan Atas Peraturan Pemerintah Nomor 42 Tahun 2006 Tentang Pelaksanaan UndangUndang Nomor 41 Tahun 2004 Tentang Wakaf Dalam Undang-Undang Nomor 41 Tahun 2004 tentang Wakaf yang memangkas alur birokrasi yang pada awalnya semua perizinan disampaikan kepada Menteri Agama, hanya sampai kepada Kantor Kementerian Agama Provinsi bagi tanah wakaf yang luasnya kurang dari $5000 \mathrm{~m}^{2}$.

\section{DAFTAR PUSTAKA}

Alquran Kementerian Agama Republik Indonesia
Direktorat Pemberdayaan Wakaf

Direktorat Jenderal Bimbingan Masyarakat Islam Departemen Agama. Fiqih Wakaf.

Direktorat Pemberdayaan Wakaf. 2007.

Paradigma Baru Wakaf di Indonesia, Cet 1. Jakarta: Dirjen Bimas Islam

Direktorat Pengembangan Zakat dan Wakaf. 2005. Wakaf Tunai dalam Perspektif Hukum Islam. Jakarta: TP

Halim, Abdul. M.A. 2005. Hukum Perwakafan di Indonesia. Jakarta: Ciputat Press.

Kahf, Monzer. 2006. al-Wagf al-Islami Tașawwuruhu, Idaratuhu, Tanmiyatuhu. Damaskus: Dar alFikr

Karim, Shamsiah Bte Abdul. 2010. Contemporary of Shari'a Compliance Structuring for the Development and Management of Wagf Asset in Singapore. Kyoto Bulletin of Islamic Area Studies pp. 143-164.

Mugniyah, Muhammad Jawad. 2010. Figh Lima Madzhab: Ja'fari, Hanafi, Syafi'i, Hambali. Jakarta: Lentera.

Mukhlisin, Muzarie. 2010. Hukum Perwakafan dan Implikasinya Terhadap Kesejateraan Umat (Implementasi Wakaf di Pondok Modern Darussalam Gontor) cet 1. Jakarta: Kementerian Agama 
Achmad, et al/Jurnal Ekonomi Syariah Teori dan Terapan Vol. 6 No. 9 September 2019: 1924-1935; IMPLEMENTASI WAKAF ISTIBDAL DALAM PEMBEBASAN LAHAN PEMBANGUNAN JALAN TOL (STUDI KASUS PEMBANGUNAN JALAN TOL SURABAYA-MOJOKERTO)

Peraturan Pemerintah Nomor 42 Tahun 2006 tentang Pelaksanaan Undang-Undang Nomor 41 Tahun 2004 tentang Wakaf dan Kompilasi Hukum Islam

Peraturan Pemerintah Republik Indonesia No. 8 Tahun 1990 Tentang Jalan Tol

Peraturan Pemerintah Republik Indonesia Nomor 25 Tahun 2018 tentang Perubahan Atas Peraturan Pemerintah Nomor 42 Tahun $2006 \quad$ Tentang Pelaksanaan Undang-Undang Nomor 41 Tahun 2004 Tentang Wakaf Dalam Undang-Undang Nomor 41 Tahun 2004 tentang Wakaf

Sugiyono. 2012. Metode Penelitian Kuantitatif Kualitatif dan R\&D. Bandung: Alfabeta.

Undang-Undang Nomor 26 Tahun 2007 Tentang Penataan Ruang. Undang-Undang Nomor 41 Tahun 2004 tentang Wakaf
Wirartha, I Made. 2006. Metodologi Penetilian Sosial Ekonomi. Yogyakarta: CV Andi Offset.

Yin, Robert. K. 2009. Studi Kasus; Desain dan Metode. Jakarta: Raja Grafindo Persada.

bpjt.pu.go.id/ (laman Badan Pengatur Jalan Tol)

www.jasamarga.com (laman Jasa Marga)

https://bwi.or.id/ (laman Badan Wakaf Indonesia)

https://katadata.co.id/ (laman perusahaan media dan riset berita ekonomi dan bisnis)

https://www.kpu.go.id/ (laman Komisi Pemilihan Umum Republik Indonesia) 